\title{
Erweiterung des Treuhandpartnernetzes für Basel und Region
}

FMH Consulting Services bietet ab 1. September 2007 mit der Ceccon Consulting \& Partner AG, Zwingen, einen weiteren Treuhandpartner in ihrem Netz an.

Jean-Pierre Ceccon, eidg. dipl. Finanzplanungsexperte, war der erste Vertrauenspartner FMH Insurance Services für BaselStadt und Baselland. Jean-Pierre Ceccon betreut mit seinem Team Ärzte in den Bereichen Vorsorge, Versicherungstreuhand, Steuerplanung, Finanzplanung sowie auch in güter- und erbrechtlichen Belangen. Im Verlauf dieser Beratungen spielt die Praxisbuchhaltung und Praxistreuhand eine wesentliche Rolle, so dass auch die Übernahme von Treuhandmandaten immer mehr erfolgten. Die Ärzte schätzen vor allem den vereinfachten administrativen Ablauf, denn sie haben von der einfachen Praxisversicherung über die komplexen Zusammenhänge der Sozialversicherungen bis zum Jahresabschluss nur einen Ansprechpartner, der innert kürzester Frist offene Fragen klären oder auch den richtigen Partner für eine Problemlösung hinzuziehen kann.

Jahrelange Erfahrungen im Bereich der Finanz- und Steuerplanung garantieren eine termingerechte und steueroptimierte Buchführung Ihrer Praxis.

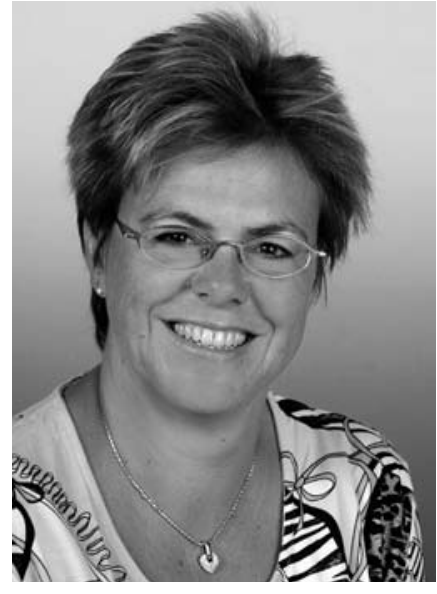

Patrizia Schmid ist seit Anfang an dabei. Sie erwarb ihr Fachwissen und ihre Fachkenntnisse in einer grossen Basler Treuhandfirma. Nebst einigen Grossmandaten betreute sie dort vorwiegend KMU und Einzelfirmen. Diese Berufserfahrungen sind in der Betreuung von Ärzten und Zahnärzten besonders wertvoll.

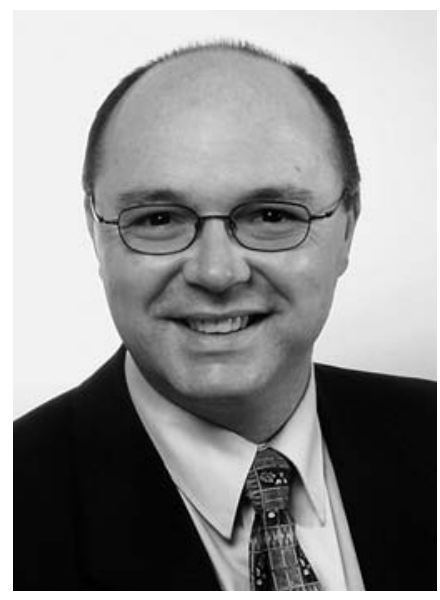

Jean-Pierre Ceccon sammelte seine Berufserfahrungen in verschiedenen Positionen in der Bank- und Versicherungswirtschaft. Dank Weiterbildungen in den Bereichen Finanz, Versicherung, Steuern und Recht betreute er vorwiegend eine anspruchsvolle Kundschaft. Er gründete 2002 sein eigenes Beratungsunternehmen.

Gerne sind wir für Sie da. Wir freuen uns auf Ihre Kontaktaufnahme.

\author{
Ceccon Consulting \& Partner AG \\ FMH Treuhand Services \\ Jean-Pierre Ceccon \\ Baslerstrasse 10 - 4222 Zwingen \\ Tel. 0612610808 a Fax 0612610805 \\ E-Mail: jean-pierre.ceccon@fmhtreuhand.ch
}

